\title{
Innovative Online Platforms: Research Opportunities
}

\author{
Ying-Ju Chen, Hong Kong University of Science and Technology \\ Tinglong Dai, Johns Hopkins University \\ C. Gizem Korpeoglu, University College London \\ Ersin Körpeoğlu, University College London \\ Ozge Sahin, Johns Hopkins University \\ Christopher S. Tang, ${ }^{1}$ University of California, Los Angeles \\ Shihong Xiao, Hong Kong University of Science and Technology
}

September 24, 2018

\begin{abstract}
Economic growth in many countries is increasingly driven by successful startups that operate as online platforms. These success stories have motivated us to define and classify various online platforms according to their business models. This study discusses strategic and operational issues arising from five types of online platforms (resource sharing, matching, crowdsourcing, review, and crowdfunding) and presents some research opportunities for operations management scholars to explore.
\end{abstract}

Keywords: Online platforms, innovative operations, operations management.

${ }^{1}$ Corresponding author. Email: chris.tang@anderson.ucla.edu.

The authors are thankful to the guest editors, Professors Saif Benjaafar and Ming Hu, two anonymous reviewers, and Daniel Freund for their constructive comments on earlier versions. 


\section{Introduction}

To understand the impact of online platforms on today's global economy, one needs to look no further than the Wall Street Journal list of the ten most valuable venture-backed private companies. As of July 2018, seven of them, including Uber ( $\$ 72$ billion), Didi-Chuxing ( $\$ 56$ billion), Airbnb ( $\$ 31$ billion), Meituan-Dianping ( $\$ 30$ billion), WeWork ( $\$ 20.2$ billion), Lufax ( $\$ 18.5$ billion), and Lyft (\$15.1 billion), ${ }^{2}$ are online platforms. Each of these platforms creates value for two or more independent user groups by facilitating transactions or relationships between them. Uber, Didi-Chuxing and Lyft connect drivers and passengers; Airbnb and WeWork connect property owners and renters for residential homes and commercial offices, respectively; Meituan-Dianping connects merchants (e.g., restaurants) and customers by combining the Groupon model of discounts and the Yelp model of consumer reviews; and Lufax connects capital seekers and capital providers. The European Commission (2015) reported that between 2001 and 2011, online platforms accounted for $55 \%$ of GDP growth in the U.S. and 30\% of GDP growth in the EU. PwC projects that platforms will generate $\$ 335$ billion in revenues worldwide by 2025 (FTC, 2016).

Amid their strong growth prospects, online platforms are controversial because they disrupt traditional businesses: Uber disrupts taxis, Airbnb disrupts hotels and Alipay (an online payment system) disrupts debit/credit cards. Also, the underlying innovative business models of different platforms are often at odds with existing policies and regulations. For example, labor lawyers have argued that Uber drivers should be treated as employees instead of contractors, and consumer activist groups have expressed concerns over Uber's safety and privacy issues. Governments around the world are struggling to review their outdated legal frameworks to regulate various online platforms.

Online platforms have generated excitement in the public domain. As of August 2018, a Google search using keywords "online platforms" or "online platform” returned over 21 million webpages. While some established literature deals with e-commerce platforms and platforms for the distribution of information goods (e.g., Geoffrion and Krishnan, 2003), limited published research exists on "many-to-many" online platforms and on online platforms that involve exchange of physical goods, labor or capital. Specifically, using keywords "online platforms" to search on the Web of Science found 721 research articles that were published between 2000 and 2017, and nearly half of them (329 articles) were published in 2017 (see Figure 1). ${ }^{3}$ Therefore, a great opportunity exists for the operations management (OM) research community to examine strategic and operational issues arising from various online platforms.

\footnotetext{
${ }^{2}$ Source: http://graphics.wsj.com/billion-dollar-club/.

3 The first two research articles (Bolton et al., 2005; Michail et al., 2005) that used the term "online platforms" were published as book chapters. The former used lab experiments to examine the implications of "online reputation" for
} 
Motivated by these observations, this study explored three main questions: (1) What is an online platform? How should one classify online platforms? (2) How do online platforms create and capture value? (3) What are the $\mathrm{OM}$ research opportunities arising from various types of online platforms?

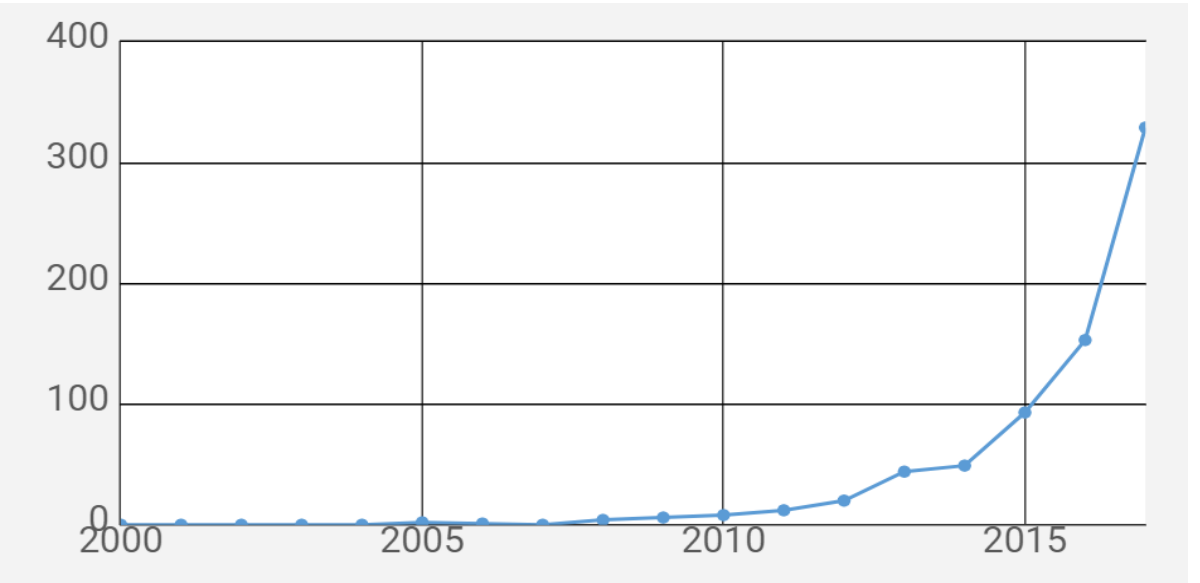

Figure 1. Number of academic publications with keywords "online platforms" in titles or abstracts.

The rest of this paper is organized as follows. Section 2 defines and classifies platforms. Section 3 discusses value created and captured by platforms. Section 4 presents potential research opportunities for OM scholars. ${ }^{4}$ Section 5 summarizes the study conclusions.

\section{Online Platforms: Definition and Classification}

The European Commission (2016) defines online platforms as digital marketplaces that "enable individuals or small entities as buyers and sellers to "transact" (i.e., search and match) effectively and efficiently by employing various internetconnected digital communication devices." Online platforms share key characteristics including 1) the use of information and communication technologies to facilitate transactions between user groups; 2) collection and use of data about these transactions; and 3) network effects that make the use of platforms with most users most valuable to other users. Examples include e-commerce platforms (e.g., Alibaba, Apple App Store), travel websites (e.g., Expedia), crowdsourcing platforms (e.g., InnoCentive), and crowdfunding platforms (e.g., Kickstarter). Figure 2 illustrates this definition of an online platform. In addition, the platform specifies "rules of engagement" (e.g., types of information, pricing formats, ratings, search process, etc.) for users to search, interact, and match with each other.

suppliers and buyers to transact over an e-commerce platform, whereas the latter discussed how Egyptian minority groups use online social media platforms for expressing their thoughts freely.

${ }^{4}$ Because the intent is to encourage OM researchers to explore this important area, this study does not provide an exhaustive review of related literature and we apologize for any unintended omissions. 


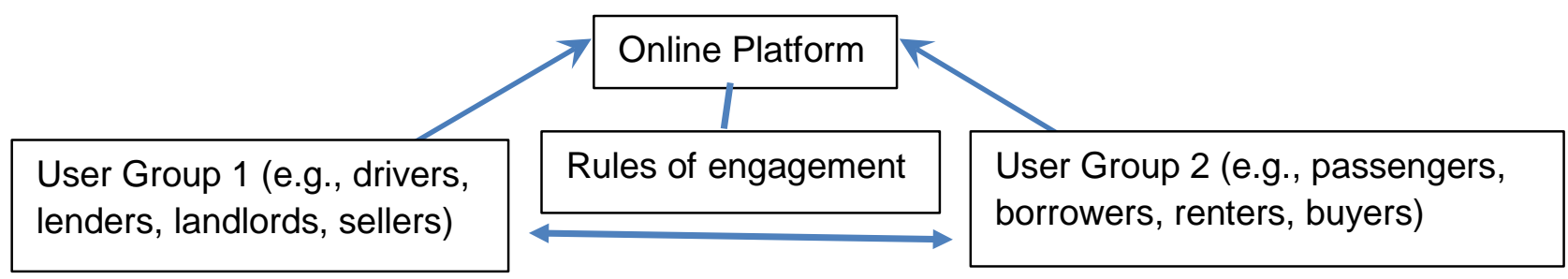

Figure 2. Interactions between an online platform and business or consumer user groups.

Since a universally accepted classification scheme for online platforms does not exist, one may take a "buyerseller perspective" to classify online platforms according to the type of transactions (e.g., service (a ride), capital (a loan), information (a review), etc.) between buyers and sellers. Alternatively, one may take a "platform perspective" by focusing on what the platform aims to facilitate (e.g., resource-sharing, matching, crowdsourcing, reviews, crowdfunding). This study adopts the second approach to classify online platforms because it enables one to map these facilitations to business models (i.e., activities to create value for buyers and sellers, and activities for the platform to capture value (Chesbrough, 2007)). Due to page limitations, we focus on resource sharing, matching, crowdsourcing, review, and crowdfunding platforms as shown in Table 1.5

(Further discussions of e-commerce and peer-to-peer lending platforms can be found in Appendices A and B, respectively.) In addition, we focus on "virtual" online platforms that "do not own inventory of physical goods or contents." 6

Table 1. Classification of online platforms according to business models and user groups.

\begin{tabular}{|l|l|l|l|}
\hline $\begin{array}{l}\text { Business Model } \backslash \\
\text { User Group }\end{array}$ & $\begin{array}{l}\text { Business to Business } \\
\text { (B2B) }\end{array}$ & $\begin{array}{l}\text { Business to Consumer } \\
\text { (B2C) }\end{array}$ & $\begin{array}{l}\text { Consumer to Consumer } \\
\text { (C2C) }\end{array}$ \\
\hline Resource Sharing & WeWork $^{7}$ & Uber Eats, Deliveroo & , Ele.me, \\
& & $\begin{array}{l}\text { Uber, Didi-Chuxing, } \\
\text { Airbnb, Yard Club, Udemy }\end{array}$ \\
\hline
\end{tabular}

\footnotetext{
${ }^{5}$ In addition to these five types of platforms, online gaming platforms are also growing. Graham (2017) reports that the annual revenue of online gaming platforms (e.g., Steam, Xbox Live Marketplace, PlayStation Store) has exceeded USD $\$ 100$ billion.

${ }^{6}$ For example, Amazon is not an online platform overall because Amazon owns inventory of its merchandise. However, Amazon Marketplace is an online platform because it enables third-party sellers to sell their products to consumers by piggybacking on the Amazon website. Similarly, the bike sharing platform OfO in China is not an online platform because it owns its fleet; however, Uber is an online platform because it does not own cars.

${ }^{7}$ WeWork is a B2B platform because it offers shared office spaces for small businesses and entrepreneurs to conduct business activities.

${ }^{8}$ Deliveroo, Ele.me and Uber Eats are online platforms that coordinate self-employed delivery persons to deliver food from restaurants to their customers using bicycles, motorcycles or cars. These platforms engage three groups of users: restaurants, freelance couriers and eaters.

${ }^{9}$ Udemy is an online education platform that enables instructors to post their online courses for free, but instructors share a portion of the revenue collected from online students. Udemy has over 15 million students and more than 20,000 instructors offering more than 55,000 online courses.
} 


\begin{tabular}{|c|c|c|c|}
\hline Matching & $\begin{array}{l}\text { Upwork (formerly known } \\
\text { as Elance) }\end{array}$ & $\begin{array}{l}\text { Monster, CareerBuilder, } \\
\text { LinkedIn (a recruitment } \\
\text { platform) }\end{array}$ & $\begin{array}{l}\text { e-Harmony, Match, } \\
\text { TaskRabbit, Tinder, } \\
\text { Instagram }^{10}\end{array}$ \\
\hline Crowdsourcing & $\begin{array}{l}\text { InnoCentive, }{ }^{11} \text { Kaggle, } \\
\text { Topcoder, NineSigma }\end{array}$ & LiveOps $^{12}$ & \\
\hline Review & & $\begin{array}{l}\text { Kelly Blue Book, Shopzilla, } \\
\text { Shopping.com }\end{array}$ & $\begin{array}{l}\text { Yelp, Rotten Tomatoes, } \\
\text { TripAdvisor, Angie's List, } \\
\text { Meituan-Dianping }\end{array}$ \\
\hline Crowdfunding ${ }^{13}$ & & Kickstarter, Indiegogo & LendingClub, Prosper \\
\hline
\end{tabular}

Without owning assets, virtual online platforms (Table 1) are essentially "intermediaries" that connect different user groups. What follows are illustrative examples for the five types of platforms. 1) Uber is a resource sharing platform that coordinates passengers and drivers for rides by leveraging real-time location information of both user groups. 2) e-Harmony is a matching platform that matches its male and female members for dating by using members' personal information and preferences. 3) InnoCentive is a crowdsourcing platform that enables many solvers to compete for developing the best solution to a problem posted by a seeker. 4) Yelp is a review platform that allows numerous users to post their reviews and share their experiences about various merchants. 5) Kickstarter is a crowdfunding platform that enables a seeker to raise funds from a large number of providers to support a project.

\section{Value Creation and Value Capture}

This section discusses how platforms create and capture value. Section 3.1 analyzes value creation and capture by various platforms, and Section 3.2 highlights the various success and risk factors of these platforms.

\subsection{Value Created and Captured by Online Platforms}

As an intermediary, a platform's success hinges on the value it creates for user groups. Wu (2004) summarized informational and transactional values created by intermediaries. The first value reduces information asymmetries between user groups and the second value reduces the costs of searching and matching. Belavina and Girotra (2012) articulated an additional value: an intermediary can reduce the matching

\footnotetext{
${ }^{10}$ Safronova (2017) reports that Instagram is now a dating platform. By using its Instagram Stories (a collage of photos, memos, comments, etc.), users can create their own online persona for potential matching.

${ }^{11}$ InnoCentive is a crowdsourcing platform that can be categorized as B2B or B2C because it contains a large number of solvers who can be considered as consumers; yet, these solvers also seek income in the form of awards.

12 LiveOps is an online service platform that connects freelancer call center agents with consumers. Their business model is categorized as crowdsourcing because a large number of call center agents are compensated based on their relative rank of service quality. See Stouras et al. (2014) for details.

${ }^{13}$ Reward-based crowdfunding (B2C) platforms such as Kickstarter are discussed in Section 4.5); the discussion of peerto-peer lending (C2C) platforms is found in Appendix B.
} 
friction between buyers and sellers to meet buyers' changing needs and sellers' changing preferences. Table 2 illustrates these different values by platforms and user groups.

Table 2. Value created by different online platforms for different user groups.

\begin{tabular}{|l|l|l|}
\hline $\begin{array}{l}\text { Business Model/ } \\
\text { Value Creation }\end{array}$ & Value Created for Businesses & Value Created for Consumers \\
\hline Resource Sharing & Reduce operating costs (e.g., WeWork). & $\begin{array}{l}\text { On-demand matching of supply and } \\
\text { demand (e.g., Uber); monetize under- } \\
\text { utilized resources (e.g., Uber and Airbnb). }\end{array}$ \\
\hline Matching & $\begin{array}{l}\text { Reduce search costs for finding a large } \\
\text { number of job applicants (e.g., Monster) or } \\
\text { freelancers (e.g., Upwork). }\end{array}$ & $\begin{array}{l}\text { Decrease search, signaling and } \\
\text { communication costs for finding partners } \\
\text { (e.g., e-Harmony) or jobs (e.g., Monster). }\end{array}$ \\
\hline Crowdsourcing & $\begin{array}{l}\text { Reduce search costs for finding a large } \\
\text { number of solvers outside the firm; elicit } \\
\text { innovative solutions to challenging problems } \\
\text { at low cost (e.g., InnoCentive). }\end{array}$ & $\begin{array}{l}\text { More income-generating opportunities with } \\
\text { easy access; opportunities to develop and } \\
\text { improve skills and reputation (e.g., } \\
\text { Topcoder). }\end{array}$ \\
\hline Review & $\begin{array}{l}\text { Attract more potential customers with better } \\
\text { reviews (e.g., Yelp). }\end{array}$ & $\begin{array}{l}\text { Reduce search costs for finding quality } \\
\text { products/services (e.g., Yelp). }\end{array}$ \\
\hline Crowdfunding & $\begin{array}{l}\text { Reduce search cost and demand uncertainty } \\
\text { for seekers (e.g., Kickstarter). }\end{array}$ & $\begin{array}{l}\text { Reduce search cost for providers to fund } \\
\text { projects that match their interest (e.g., } \\
\text { Kickstarter). }\end{array}$ \\
\hline
\end{tabular}

In addition to what Table 2 highlights, "network effects" generate a positive feedback loop in which a platform creates more values with more users. ${ }^{14}$ For example, as more recruiters post their job openings on Monster, more job seekers will post their resumes. Hence, Monster creates more value when the market size becomes bigger. ${ }^{15}$ Online platforms can also improve social welfare. Arnold and Hildebrandt (2017) stated that ride-sharing platforms such as Uber can reduce carbon dioxide emissions. Moreover, online platforms such as Etsy create new jobs for low-income women (House of Lords, 2016). ${ }^{16}$

In return for value created, an online platform can capture value (i.e., generate revenue from user groups and/or online advertisements) as summarized in Table 3.

Table 3. Value captured by different online platforms from different user groups.

\begin{tabular}{|l|l|l|}
\hline $\begin{array}{l}\text { Business Model/ } \\
\text { Value Capture }\end{array}$ & Value Captured from Businesses & Value Captured from Consumers \\
\hline Resource Sharing & $\begin{array}{l}\text { Providers pay commission fees (e.g., Uber } \\
\text { used to charge its drivers 25\% of the price } \\
\text { paid by each passenger). }\end{array}$ & $\begin{array}{l}\text { Consumers pay for the service and some other } \\
\text { processing fees, but the use of the platform is } \\
\text { free of charge. }\end{array}$ \\
\hline
\end{tabular}

\footnotetext{
14 Social media platforms exhibit strong network effects that propel the exponential growth in terms of the number of users (Cusumano, 2011). For example, within 6 years, WeChat reached almost 1 billion users (Lucas, 2017).

15 However, Li and Netessine (2018) discovered that this "positive" network effect may not be true when the user groups are heterogeneous and when searching and matching processes are either time-constrained or time-sensitive; respectively.

${ }^{16}$ However, Benjaafar et al. (2018b) find that by attracting more workers to participate in on-demand platforms that provide time-sensitive services, labor welfare is non-monotonic: it first increases in the labor pool size and then decreases.
} 


\begin{tabular}{|l|l|l|}
\hline Matching & $\begin{array}{l}\text { Business organizations pay some service } \\
\text { fees for job postings. }\end{array}$ & $\begin{array}{l}\text { Ranges from fully free platforms to one that } \\
\text { charges subscription and add-on service fees } \\
\text { (e.g., review of resumes for job seekers). Paid } \\
\text { memberships for C2C models (e.g., e- } \\
\text { Harmony). }\end{array}$ \\
\hline Crowdsourcing & $\begin{array}{l}\text { Seekers pay service fees or commissions } \\
\text { (e.g., InnoCentive charges seekers fees for } \\
\text { posting problems or commissions based } \\
\text { on the awards given to solvers). }\end{array}$ & Usually free for solvers. \\
\hline Review & $\begin{array}{l}\text { Advertising from businesses (e.g., hotel } \\
\text { ads on TripAdvisor). }\end{array}$ & $\begin{array}{l}\text { Free for consumers, but some platforms (e.g., } \\
\text { Yelp) reward consumers who post many } \\
\text { reviews. }\end{array}$ \\
\hline Crowdfunding & $\begin{array}{l}\text { Seekers pay commissions (e.g., Kickstarter } \\
\text { keeps 5\% of funds raised in each } \\
\text { successful campaign). }\end{array}$ & Usually free for providers. \\
\hline
\end{tabular}

\subsection{Success and Risk Factors of Online Platforms}

As platforms create and capture value, Parker et al. (2016) stated that, by leveraging the capability of digital technologies, platforms have the following competitive advantages over traditional businesses:

1) Low development costs. Because online platforms do not own inventories or contents, the main cost is to develop the platform itself and attract users from both sides to participate.

2) Low to medium costs of user acquisition and retention. Because online platforms are relatively new, competition among them is less fierce. As such, the costs of user acquisition and retention are relatively moderate. In particular, many online platforms provide free services for consumers even though they charge businesses service fees.

3) Multi-sided revenue streams. Because online platforms create value for both user groups, they can potentially generate revenue from each user group and from online advertisements.

4) Ease of scalability. Because online platforms are light in assets, they can easily scale up their operations both locally and globally.

5) Wide accessibility. As more user groups gain access to the Internet and mobile technologies, more user groups can gain access to the services provided by online platforms. This is particularly pertinent to the China market that has over 600 million smartphone users.

Behind successful online platforms that leverage the previous success factors, there are myriad failures. Van Alstyne et al. (2016) highlighted several key reasons why online platforms fail. First, platforms may fail to optimize "openness." For example, Apple's market penetration was in single digits until Apple opened its iOS platforms to app developers. Second, platforms may fail to launch the "right side" of the market. For example, Google launched Google Health for consumers to consolidate their health information, but it failed because it was focusing on consumers without getting support from physicians and insurers. Without the support 
from providers, consumers do not find strong reasons to use Google Health. Third, platforms may fail to put critical mass ahead of money. For example, eBay developed Billpoint: a digital payment system that can prevent fraudulent transactions. Whereas Billpoint charged transaction fees, PayPal offered financial incentive to encourage existing users who refer new users to sign up. Within a short period of time, PayPal became the preferred payment system for eBay, and eBay phased out Billpoint and acquired PayPal eventually.

Conceptually speaking, many platforms can fail due to the following three major risk factors:

1) Poor value creation. Van Alstyne et al. (2016) articulated that platforms failed because they have not created the "right" value for the "right" user group. For example, Covisint, an online platform that matches major automakers (e.g., Daimler-Chrysler, Ford, GM) with smaller auto-parts suppliers, failed because the platform created little value for participating suppliers when many suppliers had to compete for orders from a few automakers. As only a few suppliers participated, Covisint ended its operations in 2004. Also, Tang (2012) argued that Groupon creates great value to customers, but not to merchants: many merchants complain about not being able to "translate" Groupon sales based on deep discount into repeat customers paying the regular retail price. As Groupon continues to incur extra costs to recruit and retain merchants, it was rarely profitable ${ }^{17}$ and its stock price fell from its IPO price $\$ 28$ in 2011 to $\$ 5$ in August 2018 .

2) Search and matching frictions. Growing the market size is believed to be critical for online platforms (see Kabra et al. (2017) for a study of ride-hailing platforms). However, this belief may not be true because the search and matching costs for some platforms can increase as the size of different user groups increases. To elaborate, consider the empirical study of an online peer-to-peer holiday property rental platform conducted by Li and Netessine (2018). They found that as the number of participants on each side increases, search frictions can cause the number and the quality of resulting matches to reduce. ${ }^{18}$ Specifically, they found that doubling the size of travelers and hosts can create extra search costs: the number of inquiries sent by travelers increased by $18.3 \%$, and the number of inquiries received by hosts increased by 19.6\%. Also, it can create extra matching frictions: the number of traveler confirmations reduced by $15.4 \%$, and the host occupancy rate reduced by $15.9 \%$. Thus, the platform lost $5.6 \%$ of potential matches because of the increased search frictions caused by the increased market size.

3) Low switching costs. As more platforms enter the market and as competition among platforms intensifies, user groups may become disloyal due to low switching costs. Consider the Thingiverse platform that allows users to share or sell product design files to be printed on its MakerBot 3-D

\footnotetext{
${ }^{17}$ Despite its $\$ 3$ billion annual revenue since 2013, Groupon’s earnings before interest and tax has been negative until 2017.

${ }^{18} \mathrm{Li}$ and Netessine (2018) show, consistent with earlier findings, that more product choices can lead to lower sales due to "choice fatigue" (e.g., Kuksov and Villas-Boas, 2010).
} 
printers. However, because MakerBot printers are based on open-source designs, the product design files are based on industry standard file formats so that users can download design files and print the products on competitor's 3-D printers. Consequently, Thingiverse has limited growth because the company failed to develop proprietary design specs so that similar platforms (e.g., Pinshape, GrabCad, MyMiniFactory, Autodesk123D) can enter the market and disloyal users can share or sell their product design files on different platforms (Zhu and Furr, 2016). In the same vein, user groups can become disloyal because various ride-hailing platforms (e.g., Uber and Lyft) offer similar services and the switching costs between platforms for drivers and passengers are low (Bai and Tang, 2018).

\section{Research Questions}

Some operations management $(\mathrm{OM})$ research questions, summarized in Table 4, are intended to mitigate the three major risk factors in the last section that can hinder the success of online platforms. These questions can be examined through a variety of methodologies, including analytical modeling, behavioral experiments, empirical analysis and field experiments. Before discussing each OM research question in more detail, this section contains a brief review of the applicable literature. Except for the review platform, these questions are discussed by considering a specific context.

Table 4. OM research questions motivated by five types of online platforms.

\begin{tabular}{|c|c|}
\hline Platform Type (Context) & Operations Management Research Questions \\
\hline $\begin{array}{l}\text { Resource Sharing (Ride } \\
\text { Sharing) }\end{array}$ & $\begin{array}{l}\text { 1. Adequate value creation: Can a sharing platform create more value by } \\
\text { giving price-setting power to users? } \\
\text { 2. Reducing frictions and uncertainty: How can a sharing platform reduce } \\
\text { supply-demand imbalance and regulatory uncertainty? } \\
\text { 3. Sustaining user groups: How can a sharing platform mitigate the effect of } \\
\text { multi-homing by boosting user loyalty? }\end{array}$ \\
\hline Matching (Online Dating) & $\begin{array}{l}\text { 1. Adequate value creation: How should a matching platform design its } \\
\text { communication mechanisms between users? } \\
\text { 2. Reducing frictions and uncertainty: How should a matching platform } \\
\text { design its recommendation mechanism to reduce search friction? } \\
\text { 3. Sustaining user groups: How should a matching platform design its } \\
\text { pricing strategy to maintain a diverse user base? }\end{array}$ \\
\hline
\end{tabular}




\begin{tabular}{|l|l|l|} 
Crowdsourcing (Innovation & 1. & $\begin{array}{l}\text { Adequate value creation: How to create value to both solvers and seekers } \\
\text { by balancing "audacity and achievability"? } \\
\text { Reducing frictions and uncertainty: How to design rules of engagement to } \\
\text { reduce search friction? }\end{array}$ \\
2. & $\begin{array}{l}\text { Sustaining user groups: What is the impact of information design on user } \\
\text { satisfaction? }\end{array}$ \\
\hline Reviews & 1. $\begin{array}{l}\text { Adequate value creation: How does the design of a review platform } \\
\text { facilitate continuous feedback about business operations and consumer } \\
\text { preferences? } \\
\text { Reducing frictions and uncertainty: What are the tradeoffs behind a review } \\
\text { platform's choice of the accessibility of its reviews? }\end{array}$ \\
3. $\begin{array}{l}\text { Sustaining user groups: How to fight fake reviews in an effective and } \\
\text { sustainable manner to cultivate user loyalty? }\end{array}$ \\
\hline Crowdfunding (Reward- & 1. $\begin{array}{l}\text { Adequate value creation: How does platform design (e.g., information } \\
\text { disclosure policy) affect user interactions and hence value creation? }\end{array}$ \\
2. & $\begin{array}{l}\text { Reducing frictions and uncertainty: How to leverage artificial intelligence } \\
\text { (e.g., blockchains) to reduce outcome uncertainty and increase allocation } \\
\text { efficiency? } \\
\text { Sustaining user groups: How to boost user loyalty by softening inter- } \\
\text { seeker competition? }\end{array}$ \\
\hline
\end{tabular}

\subsection{Resource Sharing}

The emerging culture of the sharing economy, along with the rapidly evolving mobile technology, has given rise to numerous online $\mathrm{C} 2 \mathrm{C}$ platforms where consumers can now monetize their under-utilized resources by sharing them with other users (Economist, 2013). Some existing virtual platforms facilitate the sharing of residences (Airbnb), cars (Uber, Lyft, and Didi-Chuxing) ${ }^{19}$, boats (Boatbound), furniture (Furnishare) and equipment (Yard Club). In the context of collaborative product sharing, Benjaafar et al. (2018b) showed that product ownership and usage would be higher when the product cost is higher.

With the advent of real-time geographic location information about providers and users, the search cost to locate providers and users is low. However, the matching frictions can be high, especially when each ondemand transaction involves two entities who are unfamiliar with each other. To reduce this friction, many sharing platforms develop mechanisms to 1) foster trust by using a bilateral rating system that serves as "proxies" about the quality of both parties; and 2) enhance payment security by charging a user's pre-

\footnotetext{
${ }^{19}$ Here, we consider Uber, Lyft and Didi-Chuxing as resource sharing platform in the sense that the platform does not own physical goods, and the drivers "share" their cars with passengers.
} 
registered credit card and by allowing users to challenge the payment due to unsatisfactory services. In the first example, after each transaction (ride or stay), a user (passenger or guest) and a provider (driver or host) rate each other; and in the second example, when the host failed to deliver certain promises. While these measures can reduce search and matching frictions, the following questions are intended to provide "right" value to right user groups, to reduce search and matching frictions further, and to cultivate loyalty from both user groups.

\section{Can a sharing platform create more value by giving price-setting power to users? In recent} years, researchers and practitioners have recognized the importance of having online platforms to attract the "right" type of users (Veiga et al., 2017). One way to influence user entry is through the design of pricing mechanisms, which includes the decision regarding the price-setting entity. When Airbnb charges a commission, it is the provider (property owner) who sets the price (i.e., rent). The provider has superior information about the quality of the product (room or apartment) and can assess the value better than a central planner. Li et al. (2015) also showed empirically that "professional" owners earn more as they may get better in assessing the value of their property to others in addition to their own knowledge about quality. However, it is the platform (Uber) who sets the price and the commission fee. By comparison, HKTaxi, a taxi-hailing app, enables passengers in Hong Kong to bid for taxi rides. In view of the on-demand nature and the heterogeneity of both user groups, it is unclear which price-setting mechanism is most effective.

\section{How can a sharing platform reduce supply-demand imbalance and regulatory uncertainty?}

In addition to the ways to reduce search friction, when demand exceeds supply during peak hours, ride-hailing platforms (such as Uber and Lyft) adopt surge pricing to reduce matching friction by serving passengers with higher willingness to pay and by encouraging more drivers to participate during rush hours. In a monopoly setting, Cachon et al. (2017) found that surge pricing can outperform static pricing. Riquelme et al. (2015) characterized a small performance gap between static and surge pricing in an asymptotic regime. Chen and $\mathrm{Hu}(2018)$ found that in the presence of forward--looking drivers and riders, static pricing can deter strategic behavior and achieve asymptotic optimality. In a competitive environment, Wang and $\mathrm{Hu}(2014)$ found static pricing can sustain in equilibrium because, relative to contingent pricing, it helps soften competition. Tang and Yoo (2018) showed that a platform should not surge unless it has a competitive advantage over its competitor. However, when both user groups are heterogeneous and time-sensitive, it is not immediately clear if surge pricing is a dominant competitive strategy. For example, to compete with Uber in London, Kabbee does not adopt surge pricing (Field, 2017). In the OM literature, the conditions under which a sharing platform should adopt surge pricing and how surge pricing affects supply-demand 
imbalance deserve further examination.

A notable source of uncertainty surrounding resource-sharing platforms arises when they interact with regulators. Because a resource-sharing platform often serves a sector of public interest (e.g. transportation and housing), it must be keenly aware of the externality of its service offerings (e.g., increased congestion in major cities due to ride-hailing services). It is of interest for OM scholars to examine the interactions between platforms and regulators and to examine, from a regulator's perspective, the optimal quantity of resources allowed for sharing on such platforms. Yu et al. (2017) presented a multi-stakeholder model to examine the implications of the 2017 policy for regulating on-demand ride services in China. They showed that the Chinese government policy can result in the reduction of the number of ride-hailing service cars on the road. In 2018, the New York City (NYC) council voted to temporarily cap the total number of Uber or Lyft car licenses operating within the city. Clearly, the optimal cap depends on the competing objectives associated with different stakeholders (Yu et al., 2017, Badger et al., 2018). Hence, this new policy in NYC raises some new research questions: Should the total number of taxi licenses (including those for Uber and Lyft cars $)^{20}$ be capped? Should the number of "actively participating" Uber drivers be capped at all times or only during rush hours?

\section{How can a sharing platform mitigate the effect of multi-homing by boosting user loyalty?}

Because a sharing platform does not own or have direct control over resources (e.g., cars as assets or drivers as employees), independent providers may "multi-home". Also, due to low switching costs across platforms, customers are not loyal either. Since customers are sensitive to delay, they would choose whichever service satisfies their needs sooner. To stabilize supply and demand and to soften competition among different platforms, it is of interest to examine ways for a platform to cultivate loyal providers and customers. In this context, Chen and Sheldon (2015) showed empirically that surge pricing can induce independent drivers to work for longer hours. Scheiber (2017) reported that by alerting drivers that they are close to hitting certain earning targets, platforms can "nudge" some drivers to work for longer periods. The literature motivates additional research issues for further examination. For instance, it is interesting to note that Uber and Lyft now offer extra bonuses to drivers if the number of rides they provide over a week exceeds a certain threshold. This strategy increases switching cost for drivers so that they become more loyal to one of the platforms. To make customers more loyal, Kabbee, a UK-based ride-sharing service company that competes with

\footnotetext{
${ }^{20}$ Unlike most of places in the world, to be able to drive for Uber or Lyft in New York City, one needs to get a Taxi and Limousine Commission (TLC) driver license, which is the same license required for a taxi driver.
} 
Uber, has launched a customer loyalty program called Kabbee Treats. In the same vein, Uber offers city passes that allows user to take unlimited rides in a given period of time in certain markets. It is of interest to examine the implications of these loyalty programs in the context of online platforms.

In addition to these three questions, it is also important to examine resource sharing platforms from a provider's perspective and understand their impacts on social welfare (that includes consumer welfare), particularly when customers are delay-sensitive. Benjaafar et al. (2018a) found that as platforms increase the labor supply (e.g., the number of Uber drivers), labor welfare can increase or decrease, depending on customers' sensitivity to delay and other factors. Taylor (2018) discussed how customers' sensitivity to delay may impact the pricing and wage decisions for a service platform. Taylor found that delay sensitivity may increase price and decrease the optimal wage under certain conditions of customer valuation uncertainty and agent opportunity cost uncertainty. In terms of traffic congestion, Benjaafar et al. (2017) examined how different ride-sharing models (business-toconsumer-B2C and consumer-to-consumer-C2C) affect traffic congestion. They found that revenue maximizing platforms that prefer fewer seats being occupied would create high traffic congestion. By examining an ecosystem comprising consumers, taxi drivers, platform drivers, etc., Yu et al. (2017) found that a carefully designed regulatory policy can strike a balance among competing objectives associated with different stakeholders.

\subsection{Matching}

An online matching platform is a marketplace that brings together users who search for, interact with and establish personal (e.g., dating platforms such as e-Harmony and Match) or business (e.g., recruitment platforms such as Monster and CareerBuilder) relationships with each other. Compared to other types of platforms, online matching platforms are more involved because the user groups need to establish some form of relationships (e.g., communication, discussions, interviews, tests) before any matching can take place. In addition, each user not only has to choose another user, but also has to be chosen. For this reason, the design of matching platforms often follows reasoning drastically different from the design of other types of platforms (Wright, 2004).

Relative to a traditional format, an online interface helps remove physical limitations such as geography, presence, time and scale. As noted in Section 3.3, accessibility and scalability have enabled matching platforms to thrive in the online marketplace. For example, the Pew Research Center reports that $15 \%$ of adults in the U.S. used online dating sites in 2016. Also, the online dating industry is worth USD $\$ 2$ billion in the U.S. and USD $\$ 1.6$ billion in China. To capture the economic value, most online matching platforms adopt a 
subscription-based model that charges users fees for access or an advertising-based model that offers the service for free. ${ }^{21}$ However, job search platforms (Monster and CareerBuilder) charge recruiters on a "pay as you go" basis, but offer services for free to job seekers.

The limited and yet fast-expanding literature on online matching platforms has touched upon several aspects. For example, Allon et al. (2017) examined whether an online matching platform (e.g., Upwork) can capture value by using different tests to certify that service providers' skills (e.g., app or web programming) are above certain thresholds. Also, there is a need to understand the risks and costs that are unique to online matching platforms such as over-communication (Kanoria and Saban, 2017), and choice overload (Schwartz, 2004; D'Angelo and Toma, 2016). In addition, the economics literature on marriage focuses on vertical quality differentiation across users such that each user can be of either "high type" or "low type" and their types are observable and static (see, e.g., Becker, 1973; Burdett and Coles, 1997; Damiano and Li, 2007). It is important to incorporate subjective, idiosyncratic and personalized user preferences, to develop recommendations systems to improve match quality and to investigate the interaction of pricing mechanisms on user behavior, revenues and welfare in dating and matching markets. Surrounding these issues, there are several research opportunities for OM scholars:

\section{How should a matching platform design its communication mechanisms between users to} improve value creation? Users of online matching platforms may incur high search costs due to too many options and high matching costs due to choice overload and over-communication. Allon et al. (2012) examined whether an online matching platform (e.g., Upwork) should provide additional job posting and job search mechanisms to improve the matching efficiency. They found that these mechanisms can be detrimental to the matching platform unless the platform allows providers to communicate among themselves and exchange information on prices and job requirements. This finding is relevant to online dating platforms as well because, due to low communication barriers and a large user base, male users tend to "over-communicate" by sending an excessive number of low quality messages to female users, who end up paying little attention to each message. To overcome this challenge, Bumble (an online dating platform) only allows female users to initiate communication (Kanoria and Saban, 2017). Future research may explore other communication mechanisms and broaden the scope to other types of matching platforms (e.g., Monster, Upwork): Should the platform impose fees to earn the right to initiate communications? Would such a fee improve the

\footnotetext{
${ }^{21}$ In some cases, users are required to pay additional fees to access advanced features and options (e.g., Match's “pay-torespond" model that requires free users to pay to be able to respond to paying users). Some online matching platforms capture value by charging business users for each lead generated by the platform (e.g. Thumbtack) or for access to B2B matching applications that facilitate business contracting opportunities (Gee, 2017).
} 
quality and the quantity of matches? Can a platform change user behavior by disclosing information about user communication frequencies (i.e., a matching platform may display each user's total number of sent and received messages)? By requiring a fee for initiating communication or by disclosing users' communication styles, a platform may be able to create a "self-enforcing" effect, which may improve the quality of matching.

\section{How should a matching platform design its recommendation mechanism to reduce search}

friction? Online matching platforms rely on algorithms to recommend potential matchings. Halaburda et al. (2017) showed that making fewer recommendations to each user can increase both the quantity and the quality of matches in online dating platforms. The intuition is because when users are faced with many recommendations, they are less likely to accept a recommendation, reducing the chance of finding a successful match. Although the literature assumes static and myopic user preferences and behavior, future research can incorporate richer searching and matching dynamics as well as user learning. Research along this line can help online matching platforms design a recommendation system that considers intertemporal preferences of users, choice overload and leaning.

\section{How should an online matching platform design its pricing strategy to maintain a diverse} user base? Online matching platforms use different business models and pricing strategies to engage their users (Rudder, 2010; Slater, 2013). Because "a large, active, and demographically interesting user base is usually a (matching) platform's most precious asset" (Van Dijck, 2013, p. 36), managing user composition through pricing is an interesting issue. For instance, online matching platforms can use pricing strategies that "allow for self-selection of types" of users participating on the platforms (Belleflamme and Peitz, 2015, p. 649). In a matching environment where user quality is highly subjective and the value of a match is uncertain, Dai et al. (2018) showed that a matching platform can use a "refund" mechanism to attract a diversified user base that can improve the revenues and social welfare in the presence of "heterophilly-seeking" users.

\subsection{Crowdsourcing}

An online crowdsourcing platform enables a "seeker" to organize "crowdsourcing contests" so that the seeker can elicit the best solution(s) to a problem from a large group of "solvers". Such a platform (e.g., InnoCentive, Topcoder) administers contests on behalf of seekers and helps seekers to elicit solutions from a group of highly-qualified solvers. For example, InnoCentive organizes ideation, theoretical and reduction-topractice contests in which a seeker can elicit innovative ideas, theoretical solutions and validated prototypes; 
respectively. Also, some crowdsourcing platforms help seekers in determining contest rules such as an award scheme to maximize satisfaction of both user groups. Indeed, many companies with their own in-house R\&D units, such as IBM, HP, P\&G and Pfizer, are increasingly turning to crowdsourcing platforms for solutions to various problems. According to Deloitte (2016), "85\% of the top global brands have used crowdsourcing in the last ten years; and by $2018,75 \%$ of the world's high performing enterprises will be using crowdsourcing."

The OM literature on crowdsourcing contests can be divided into two streams. The first stream deals with the rules of engagement in any (online or offline) crowdsourcing contest such as the format of the contest (i.e., open to all solvers or restricts entry) and the award scheme (Ales et al., 2017b). Terwiesch and Xu (2008) showed that it is always optimal to allow free-entry open-innovation contests because the seeker can access a diverse set of solutions. Interestingly, Boudreau et al. (2011) showed empirically and Ales et al. (2018) showed theoretically that free entry is optimal only when the output of solvers is highly uncertain. This is because in the presence of a large number of solvers in a contest, generally solvers put in less effort, which dominates the diversity effect. Boudreau et al. (2016) examined empirically and Körpeoğlu and Cho (2017) examined theoretically the impact of solver heterogeneity and showed that solvers can react differently to more intense competition.

The second stream of literature examines the rules of engagement in the context of an online platform. For example, Jiang et al. (2016), Bimpikis et al. (2017), Mihm and Schlapp (2017) and Wooten and Ulrich (2017) studied whether, when and how a seeker should provide feedback to solvers. Similarly, Bockstedt et al. (2016) characterized solvers' entry behavior when their submissions are publicly shared with all solvers. Körpeoğlu et al. (2018) analyzed whether the seeker should organize multiple contests and whether the seeker should discourage solvers from working on multiple contests in parallel. Hu and Wang (2017) examined whether the seeker should run component-wise (i.e., sequential) contests or a single comprehensive (i.e., simultaneous) contest. Korpeoglu et al. (2018) analyzed the optimal contest duration from a seeker's perspective. Building on these two streams of literature, the following research questions are proposed:

\section{How to create value to both solvers and seekers by balancing "audacity and achievability"?}

Compared to a traditional research and development process, innovation contests create value through attracting a heterogeneous pool of participants from diverse disciplines. Thus, keeping the goal of a contest as general as possible helps attract solvers with diverse backgrounds. On the other hand, overly general goals may result in either pre-existing or infeasible solutions for seekers. Therefore, a crucial tradeoff in designing innovation contests is between "audacity and achievability" (Zachary, 2008). Where some platforms such as InnoCentive allow seekers to post broadly defined 
problems with subjective evaluation criteria, other platforms such as Kaggle and Topcoder usually run contests with well-defined problems and evaluation criteria. Broadly defined problems may lead to a more diverse set of solutions but well-defined problems may lead to larger, more focused efforts from solvers. Similarly, evaluating solutions based on objective criteria may reduce the uncertainty of solvers but subjective evaluation criteria give seekers more flexibility when defining problems. Thus, it is of interest to theoretically and empirically analyze the impact of problem specifications and the objectivity of evaluation criteria on the outcome of a crowdsourcing contest.

2. How to design rules of engagement to reduce search frictions? As of 2018, InnoCentive has attracted over 380,000 registered solvers, hosted more than 2,000 “external challenges" and received more than 62,000 solutions. With such a large scale, search friction naturally arises as a key consideration in designing innovation contests, but the issue of search friction is little explored in the literature, which largely treats a seeker as a monopolist principal to a group of solvers without considering the impact of competition among seekers. Yet on an online platform, seekers compete for solvers' attention and time. Such competition effect drives the value proposition and growth of a platform. Thus, it is important to analyze contest-design rules such as whether to run an open contest, and whether and how to give feedback when seekers compete for the attention of solvers. Interviews with practitioners at InnoCentive and Topcoder revealed that these platforms either make important design decisions (e.g., award scheme) on behalf of seekers or guide seekers about such decisions. Therefore, it is of interest to analyze both theoretically and empirically how a platform should guide seekers who compete for the attention of solvers. Another related question is how an increased number of contests and members affects the welfare of solvers.

3. What is the impact of information design on user satisfaction? The importance of cultivating a loyal user base is self-evident because the success of a crowdsourcing platform hinges on the growth of its registered solvers and seekers, which in turn depends on the solvers' and seekers' expected returns. An exciting research opportunity in this space lies in the application of the theory of information design (see, e.g., Bergemann et al., 2018). For instance, to improve the solvers' potential earnings, the platform needs to decide whether to promote its registered solvers by providing data analytics tools. These tools can help solvers understand their likelihood of winning a particular contest and recommend contests based on their inclination and past performance, accompanied by information as simple as the number of solvers participating in the contest, ratings and expertise. The information made available to users has implications on the type and number of solvers attracted to the contest. These issues can be investigated both empirically, experimentally and theoretically. It is also useful to model the credibility of such tools and how a specific information environment 
interacts with agents' strategic behavior. Therefore, it is of interest to examine whether the type of information environment that those platforms should offer to help its users succeed and in return, win loyalty from them.

\subsection{Review}

Online review platforms serve as online channels for different affinity groups of consumers to post reviews about certain products or services and for potential consumers to make informed purchasing decisions. Online review platforms are often specialized; for example, Yelp focuses on local business reviews and TripAdvisor focuses on hotel, restaurant and airline reviews. Review platforms "pull" a large number of buyers to submit their reviews (e.g., restaurant reviews on Yelp) without offering any monetary compensation. By posting their reviews online, buyers create "altruistic" values such as promoting a firm for providing good service, helping other consumers, feeling good when other consumers appreciate their reviews, and punishing a firm for providing bad service (Yoo and Gretzel, 2008; Hennig-Thurau et al., 2004). Although the reviews posted on review platforms are subjective and difficult to verify, online reviews serve as a form of word-of-mouth that can influence consumer perception and purchasing decisions. Goldsmith and Horowitz (2006) showed that consumers seek information from other consumers' online reviews to reduce their purchasing risks (high price, low quality, etc.). According to eMarketer (2016), 80.7\% of 1,132 Internet users said that online reviews are important to their online purchasing decisions. Also, Pew Research Center (2016) reported that more than half of internet users read online reviews before making their purchasing decisions.

There are two main streams of literature on online review platforms. The first stream examines the impact of online reviews on sales. Luca (2011) showed that a one-star increase in Yelp rating leads to a 5.9\% increase in the revenue of an independent restaurant but not on the revenue of a chain restaurant. Yet, researchers focusing on different industries find mixed results, and the reader is referred to Zhu and Zhang (2010) for a comprehensive review about the impact of customer ratings on movie and book sales. The second stream examines the issue of fake reviews. By noting that competition may induce some firms to create fake reviews for themselves and their competitors, Luca and Zervas (2016) used fake reviews rejected by Yelp's filtering algorithm to identify the reasons (e.g., poor online reputation, fierce competition) for restaurants to commit review fraud. Recognizing the presence of fake reviews, Ayeh et al. (2013), Filieri et al. (2015) and Filieri (2016) used data collected from TripAdvisor to examine the factors that can improve the trustworthiness of online reviews. These factors include the reputation of the platform, user experience with the platform, the content, and the style of the reviews. Below are three sets of proposed research questions for OM scholars: 


\section{How does the design of a review platform facilitate continuous feedback about business}

operations and consumer preferences? A static view of a review platform is that it creates value to businesses and consumers by providing a sufficiently large number of views reflective of the quality of the goods and products. Such a view does not account for dynamic interactions between businesses and customers. Thus, an area of interest to OM scholars involves feedback mechanisms between businesses and consumers. Businesses use customer feedback to improve their operations on an ongoing basis, while customers gain an updated view of how product/service quality evolves because of their reviews. Indeed, it is plausible to believe that customers' willingness to contribute reviews grows in the presence of a rational expectation that their effort will make a difference not only to peers but also to business operations. With the rise of companies like HappyOrNot that provides real time, data-driven consulting services in addition to helping collect reviews (Owen, 2018), one can expect empirical studies, field experiments, as well as analytical modeling, to be valuable tools for conducting future research in this area.

Ways to boost the number of reviews can also be a potential research topic. Conflict of interest arises when a firm (e.g., a restaurant) provides financial incentives to its own customers for posting (presumably positive) reviews. Without any incentive, Dellarocas (2003) commented that voluntary customer reviews will be under-reported because reviews are "public goods" and no incentive exists for posting reviews or for a consumer to take the risk to try new products or services. HennigThurau et al. (2004) showed that providing economic incentives is critical for an online review platform. Indeed, Yelp offers its loyal members (e.g., "Yelp Elite" members who provide wellwritten reviews and high-quality tips for consumers) free tickets for special events and invitations to try out new businesses. In this way, new businesses can get some ratings on Yelp and Yelp can help them improve their service, thereby creating a virtuous cycle. On the other hand, when an online review platform provides economic incentives for customers to post reviews, it remains unclear how these incentives impact the trustworthiness of these reviews. It calls for both empirical and experimental studies. Additionally, it is important to analyze whether and how the platform should pay customers for writing reviews. In light of competition among online review platforms, it is of interest to examine how platforms should compete for more high-quality reviews by offering appropriate incentives.

\section{What are the tradeoffs behind a review platform's choice of the accessibility of its reviews?}

To create value for heterogeneous customers, some review platforms offer different ways for customers to search for relevant reviews. For example, TripAdvisor allows customers to search reviews by traveler type. With simple search mechanisms, customers gain easy access to relevant 
information. However, it remains unclear whether this improves customer welfare and how it influences the platform's profit. Moreover, some platforms such as Tmall and Expedia choose not to provide simple search mechanisms for customer search. Hence, it is of interest to examine the impact of the provision of different search mechanisms on the value created for different user groups: under what conditions should a platform provide which type of search mechanisms?

\section{How to fight fake reviews in an effective and sustainable manner to cultivate user loyalty?}

The reputation of a review platform is likely its single most important asset. When a platform is flooded with fake reviews, users will lose their confidence in the platform and flee to its competitors. ${ }^{22}$ Indeed, a sizable worldwide ecosystem specializes in creating fake positive reviews (Stevens and Emont, 2018). On the other hand, some sellers, in addition to posting fake reviews of their own products and services, "viciously bad-mouth the competition" (Bhide, 2018). Such shady practices, despite affecting consumer welfare and day-to-day operations of numerous businesses (and their competitors), deserve some consideration.

Another issue of note is that reviews on some platforms are one sided in the sense that only customers can post reviews about firms, but firms cannot post reviews about their customers or respond to a review posted by a customer. However, a one-sided review system may give rise to unpleasant outcomes such as customers being overly positive or negative because customers can be biased and a one-sided review system gives more power to customers. To balance the power between firms and customers, and to enable other customers to calibrate the credibility of reviews, it is of interest to examine the reviewers' behavior when the platform operates under a unilateral rating system (e.g., Yelp) versus under a bilateral ratings system (e.g., TripAdvisor). Recent OM literature (e.g., Jin et al. 2018) examined the effect of bilateral ratings on a resource-sharing platform (e.g., Uber). Further research can study how user behavior under various rating systems affect the credibility of reviews on a review platform and thus interacts with the operations of various businesses.

\subsection{Crowdfunding}

A crowdfunding platform enables a capital "seeker" to collect small contributions from a large number of capital "providers" to fund a project that can range from an art project such as a music album (e.g., ArtistShare) to a business project such as a smartwatch startup (e.g., Kickstarter). Crowdfunding can take the form of B2C such as charity-based (making donations), debt-based (in exchange for interest payments),

\footnotetext{
22 On a related note, reviews that reflect only extreme opinions (i.e., only extremely satisfied and unsatisfied reviews) also negatively affect user utility, albeit in a different way.
} 
equity-based (in exchange for company shares), reward-based (in exchange for future products) crowdfunding; or in the form of $\mathrm{C} 2 \mathrm{C}$ such as peer-to-peer (P2P) lending (in exchange for interest payments). A seeker who runs a crowdfunding campaign decides on the funding target, the pledge price, and the type of funding. The funding target is the level of funds necessary for the campaign to succeed, and the pledge price ${ }^{23}$ is the level of contribution that entitles a provider to receive the product as a reward from the seeker if the campaign becomes successful. In terms of type of funding, a seeker may run a fixed-funding or a flexible-funding campaign. Under fixed funding, if the campaign becomes successful, the seeker gains access to contributions and each provider receives the finished product (reward) from the seeker when it becomes available. If the campaign fails, contributions are refunded to providers. Under flexible funding, the seeker can keep contributions regardless of the campaign's success ${ }^{24}$ so contributions may not be refunded back to providers if the campaign fails.

A crowdfunding platform runs campaigns on behalf of seekers (also called entrepreneurs or project creators) to raise funds from providers (also called contributors or backers) by introducing seekers to a large number of registered providers who are already interested in contributing to crowdfunding campaigns. In return, it charges seekers certain commissions; for example, Kickstarter helped seekers raise more than USD \$3.7 billion through 145,000 successful campaigns and it monetized its service by charging $5 \%$ of the funds raised for each successful campaign (Kickstarter, 2018). At the same time, a crowdfunding platform (e.g., Kickstarter) reduces search costs for providers by categorizing campaigns based on subjects (e.g., film, games and music) and based on success so far (e.g., percentage of funding target reached). Furthermore, a crowdfunding platform (e.g., Kickstarter) reduces providers' uncertainty by 1) keeping contributions and not releasing them to the seeker until the campaign becomes successful because otherwise, if the campaign fails, the seeker may not be willing to refund contributions back to providers; and 2) by requiring seekers to share a prototype of the finished product along with other relevant information and to include an estimated delivery date.

The OM literature on crowdfunding can be categorized into two streams: The first stream examines when a seeker should run a crowdfunding campaign (instead of asking venture capitalists for funds) and how a seeker should design its campaign to maximize the success probability and profit. For instance, Roma et al. (2018) showed that a crowdfunding campaign is desirable only for a small funding target. Babich et al. (2017) showed that when a crowdfunding campaign raises large funds, venture capitalists are discouraged to invest in

\footnotetext{
${ }^{23}$ In many instances, a seeker may offer multiple levels of pledge prices associated with different reward levels.

${ }^{24}$ However, the seeker still needs to keep the promise by completing the project and pay a commission to the platform (e.g., Indiegogo).
} 
this project. Along these lines, Hu et al. (2015) showed that when providers are sufficiently heterogeneous, a seeker should offer a menu of products instead of offering a single product. Chakraborty and Swinney (2017) found that a seeker should signal the quality of its product by using the funding target instead of the pledge price; Chang (2017) showed that a seeker's profit under fixed funding is larger than that under flexible funding.

On a more technical front, Alaei et al. (2018) provided guidelines for seekers on the design of crowdfunding campaigns by introducing a stochastic process for the sequential arrival of providers. In addition to these theoretical papers, empirical research has also explored issues such as product quality (Mollick, 2014), intracampaign updates (Du et al., 2017), and availability of contributors' identity (Burtch et al., 2015). The second stream focuses on the mechanism design of a crowdfunding platform. Strausz (2017) examined the implications of the deferred payment mechanisms. Belavina et al. (2018) compared two specific mechanisms that implement deferred payments as a way to alleviate two biggest risks providers face: the risk that seekers keep providers' contributions despite not delivering products and the risk that seekers misrepresent their product features. In one mechanism, the campaign stops as soon as the funding target is reached and providers who could not contribute to the campaign are given a chance to buy the product only after it has been developed. In the other mechanism, the platform keeps any funds raised beyond the funding target and releases only if the seeker successfully develops the product. In light of the literature and industry practice, the following research questions are proposed:

\section{How does platform design (e.g., information disclosure policy) impact user interactions and} value creation? To generate insights into how a crowdfunding platform improves its value creation, it is of interest to examine how platform design impacts the interactions between its users. For example, a platform often allows seekers to provide updates after their campaigns start. Then, an important design-related question entails whether a seeker should strategically disclose desirable features of its product dynamically over time especially when providers use the disclosed features to form certain "benchmarks". If the seeker discloses all desirable features of its product at the beginning of the campaign, it attracts more providers early on but few later on (due to no new features relative to the benchmark). If the seeker discloses partial information initially and then disclose the remaining desirable features later on, it can elevate providers' interest at different stages of the campaign but it cannot attract too many providers initially. Therefore, it is of interest to analyze a seeker's optimal dynamic information disclosure policy.

\section{How to leverage smart contracts (e.g., blockchains) to reduce outcome uncertainty and increase allocation efficiency? From the provider's perspective, the biggest risk factor of}


crowdfunding is uncertainty regarding the outcome of campaigns, due to the issue of moral hazard. One way to reduce (and possibly eliminate) such uncertainty is to implement, for example, a dominant assurance contract (Bagnoli and Lipman, 1989). Thanks to technological advances, such contracts can be implemented by blockchain technology, which can help create a "smart contract," using "Ether-on-astick" (Blockchain at Berkeley, 2017), which partially pays out to be specified seeker if and only if the providers (or an independent third party) vote that a promise has been delivered. This topic is an exciting area where OM scholars can contribute to the interface between operations management and information technology.

3. How to boost user loyalty by softening inter-seeker competition? Where the crowdfunding literature restricts attention to a single seeker, in practice, multiple seekers compete for providers' contributions. An important research opportunity is to examine how a platform should screen and select campaigns by considering competition among seekers. On one hand, running too many campaigns may lead to less exposure for each campaign and a larger dispersion of providers' contributions, so it may reduce the success probability of each campaign. On the other hand, as the number of campaigns increases, the number of trials for a successful campaign increases, so it may increase the number of successful campaigns, and hence may increase platform commissions. Similarly, a platform should select the right assortment of campaigns to maximize the contributions and success of campaigns. It is not clear how different assortments of campaigns interact with each other and providers' attention. Thus, it is of interest to examine whether and how a platform should screen and select campaigns proposed by seekers.

This section provided a brief review of recent literature and then proposed a set of OM research questions as summarized in Table 4. Because online platforms are based on different innovative business models, the proposed research questions are non-traditional. We hope these questions would motivate OM researchers to develop exciting, and novel research in the area of online platforms.

\section{Conclusions}

Motivated by the success and risk factors of online platforms stated in Section 3.2, this paper has defined and classified these platforms and described the mechanisms by which these platforms create value for different user groups and capture value for themselves. This paper has also examined the recent literature on each type of platform and proposed research questions for OM scholars to explore. 
In addition to the questions proposed in Table 4, several emerging issues will inspire future research. First, trust is a challenging issue for online platforms. For example, consider an e-commerce platform such as Alibaba's Taobao. Wang and Armstrong (2017) reported that, despite Alibaba has sued its sellers for selling counterfeit goods in 2017, 50\% of goods sold on Taobao are still fake or infringing on the intellectual property rights of others. In the same vein, many users are concerned about the safety of meeting someone online especially when the true identity of users is difficult to verify and authenticate online. To overcome the trust issues, some online platforms are using blockchain technology, i.e., a distributed ledger managed by a peer-to-peer network collectively adhering to a protocol for recording, verifying and validating new entries. Specifically, by applying the blockchain technology, an online platform can track and trace a product in a supply chain ${ }^{25}$ or a person within a social network. For example, on a blockchain-powered online dating platform called Matchpool, users act as "matchmakers" for their friends and niche groups by creating "pools." To join a pool, depending on its customized rule, a participant might need to pay an entrance fee or subscription fee; the matchmakers receive dividends from revenue generated from their pools. ${ }^{26}$ However, it is of interest to examine the impact of the blockchain technology on users' trust level of different online platforms. For instance, can blockchain technology reduce the sales of fake products online? Will users feel more secure if they transact on platforms powered by the blockchain technology? These questions beg for answers as more firms are adopting this technology.

Second, this paper discussed online platforms by focusing on Web-based or mobile-based platforms. However, the mobile platform can open up new avenues for OM researchers because mobile phones are more accessible and affordable than internet access on desktop computers, especially in the developing countries. More importantly, mobile platforms offer real time location data of the users that can enable online review platforms such as Yelp to create more value by offering real time location-based advertisements to target customers. Also, online dating platforms such as OkCupid have unveiled a geo-location app to help connect singles living near each other. Hence, it is of interest to examine how online platforms can leverage real time location data of their users to create more value for user groups and capture more value for themselves.

\footnotetext{
${ }^{25}$ Walmart, Nestle, and Unilever have formed a partnership with IBM to apply blockchain technology to improve the traceability of their food supply chains so that these firms can improve food safety (Hackett, 2017).

${ }^{26}$ For details about how matchmakers receive dividends from their pools, see: https://blog.coinfund.io /https-medium-com-flexthought-matchpool-community-owned-social-matchmaking-blockchain-71ae6129f584$\underline{71 a e 6129 f 584 .}$
} 
Third, an online review platform is an efficient way for user groups to form affinity groups so that they can share their personal experience. However, personal experience is subjective and it is not verifiable. As such, legitimate concerns exist about fake reviews. However, other types of platforms based on more objective comments can be validated by experts. Specifically, in emerging markets, NGOs and governments have established various peer-to-peer knowledge-sharing platforms that are intended to enable farmers to post and respond to queries about farming techniques. Unlike the review platforms discussed in Section 4.4, the suggestions provided by farmers can be examined and rated by experts (see, for example, Chen et al., 2015 for Avvaj Otalo, and Xiao et al., 2017 for WeFarm). When comments and reviews can be rated by independent experts and/or by other peer farmers (after they followed the advice), it is of interest to examine if farmers are more willing to offer better advice to other farmers.

As digital platforms continue to flourish in the business world, an excellent opportunity arises for OM researchers to explore numerous exciting research topics and make an impact in this important field.

\section{References}

Agrawal, V., Atasu, A., and Van Wassenhove, L. 2017. New Opportunities for Operations Management Research in Sustainability. Forthcoming, Manufacturing \& Service Operations Management.

Alaei, S., Malekian, A., Mostagir, M. 2018. A Dynamic Model of Crowdfunding. Working paper, University of Michigan, Ann Arbor.

Ales, L., Cho, S.-H., Körpeoğlu, E. 2018. Innovation Tournaments with Multiple Contributors. Working paper, Carnegie Mellon University, Pittsburgh.

Ales, L., Cho, S.-H., Körpeoğlu, E. 2017a. Innovation and Crowdsourcing Contests. Hu, M., eds., Sharing Economy: Making Supply Meet Demand, Springer Series in Supply Chain Management. To Appear.

Ales, L., Cho, S.-H., Körpeoğlu, E. 2017b. Optimal Award Scheme in Innovation Tournaments. Operations Research. 65(3) 693-702.

Allon, G., Bassamboo, A., Cil, E.B. 2012. Large-Scale Service Marketplaces: The Role of the Moderating Firm. Management Science. 58(10) 1854-1872.

Allon, G., Bassamboo, A., Cil, E.B. 2017. Skill Management in Large-Scale Service Marketplaces. Production and Operations Management. 26(11) 2050-2070.

Arnold, R., and Hildebrandt, C. 2017. The Socio-Economic Impact of Online Platforms. Research Brief. June 2017. Wissenschaftliches Institut for Infrastruktur und Kommunikationsdienste.

Ayeh, J. K., Au, N., Law, R. 2013. Do We Believe in Tripadvisor? Journal of Travel Research. 52(4) 437-453.

Babich, V., Marinesi, S., Tsoukalas, G. 2017. Does Crowdfunding Benefit Entrepreneurs and Venture Capital Investors? Working Paper, University of Pennsylvania, Philadelphia. 
Badger, E. 2018. What's the Right Number of Taxis (or Uber or Lyft Cars) in a City? New York Times (August 10).

Bagnoli, M., L. Bart. 1989. Provision of public goods: Fully implementing the core through private contributions. Review of Economic Studies 56(4) 583-601.

Bai, J., So, K.C., Tang, C.S., Chen, X., and Wang, H. 2017. Coordinating Supply and Demand on an Ondemand Service Platform: Price, Wage, and Payout Ratio. Forthcoming, Manufacturing \& Service Operations Management.

Bai, J., Tang, C.S. 2018. Can Multiple On-Demand Service Platforms Coexist? Working Paper, UCLA Anderson School of Management.

Becker, G. S. 1973. A Theory of Marriage: Part I. Journal of Political Economy. 81(4) 813-846.

Belavina, E., Girotra, K. 2012. The Relational Advantage of Intermediation. Management Science, 58(9) 16141631.

Belavina, E., Marinesi, S., Tsoukalas, G. 2018. Designing Crowdfunding Platform Rules to Deter Misconduct. Working paper, University of Pennsylvania, Philadelphia.

Belleflamme, P., Peitz, M. 2015. Industrial Organization: Markets and Strategies. Cambridge University Press, Cambridge UK.

Benjaafar, S., Bernhard, H., Courcoubetis, C. 2017. Drivers, Riders, and Service Providers: The Impact of the Sharing Economy on Mobility. Working paper, University of Minnesota.

Benjaafar, S., Ding, J.Y., Kong, G., and Taylor, T. 2018a. Labor Welfare in On-Demand Service Platforms. Working paper, University of Minnesota.

Benjaafar, S., Kong, G., Li, X., and Courcoubetis, C., 2018b. Peer-to-Peer Product Sharing: Implications for Ownership, Usage, and Social Welfare in the Sharing Economy. Management Science.

https://doi.org/10.1287/mnsc.2017.2970

Bergemann, D., Bonatti, A. and Smolin, A., 2018. The Design and Price of Information. American Economic Review, 108(1) 1-48.

Bhide, A. 2018. Skepticism Beats Snopes as an Antidote to Fake News. Wall Street Journal (June 8).

Bimpikis, K., Ehsani, S., Mostagir, M. 2017. Designing Dynamic Contests. Forthcoming, Operations Research.

Blockchain at Berkeley. 2018. Ethereum and Smart Contracts: Enabling a Decentralized Future.

https://github.com/rustielin/Blockchain-Notes/blob/master/note7.md Accessed August 16, 2018.

Bockstedt, J. Druehl, C., Mishra, A. 2016. Heterogeneous Submission Behavior and its Implications for Success in Innovation Contests with Public Submissions. Production and Operations Management. 25(7) 11571176.

Bolton, G.E., Katok, E., Ockenfels, A. 2005. Bridging the Trust Gap in Electronic Markets: A Strategic Framework for Empirical Study. Applications of Supply Chain Management and e-Commerce Research, Eds. Geunes, J; Akcali, E; Pardalos, PM; Romeijn, HE; Shen, ZJ. Springer Publishers, New York.

Boudreau, K. J., Lacetera, N., Lakhani, K. R. 2011. Incentives and Problem Uncertainty in Innovation Contests: An Empirical Analysis. Management Science. 57(5) 843-863. 
Boudreau, K. J., Lakhani, K. R., Menietti, M. 2016. Performance Responses to Competition Across SkillLevels in Rank Order Tournaments: Field Evidence and Implications for Tournament Design. RAND Journal of Economics. 47 140-165.

Burdett, K. and Coles, M.G. 1997. Marriage and Class. Quarterly Journal of Economics. 112(1) 141-168.

Burtch, G., Ghose, A., Wattal, S. 2015. The Hidden Cost of Accommodating Crowdfunder Privacy Preferences: A Randomized Field Experiment. Management Science. 61(5) 949-962.

Cachon G. P., Daniels K. M., and Lobel R. 2017. The Role of Surge Pricing on a Service Platform with Selfscheduling Capacity. Forthcoming, Manufacturing \& Service Operations Management.

Chakraborty, S., Swinney, R. 2017. Signaling to the Crowd: Private Quality Information and Rewards-based Crowdfunding. Working paper, Duke University, Durham.

Chang, J.-W. 2017. The Economics of Crowdfunding. Working paper, California State University, Fullerton.

Chevalier, J.A., Dover, Y., Mayzlin, D. 2018. Channels of Impact: User Reviews when Quality is Dynamic and Managers Respond. Forthcoming, Marketing Science.

Chen, Y., Hu, M. 2018. Pricing and Matching with Forward-Looking Buyers and Sellers. Rotman School of Management Working Paper.

Chen, M.K., Sheldon, M. 2015. Dynamic Pricing in a Labor Market: Surge Pricing and Flexible Work on the Uber Platform. Working paper, University of California, Los Angeles.

Chen, Y.-J., Shantikumar, J.G., Shen, Z.J.M. 2015. Incentive for Peer-to-Peer Knowledge Sharing Among Farmers in Developing Economies. Production and Operations Management. 24(9) 1430-1440.

Chesbrough. H. 2007. Business Model Innovations: It Is Not Just about Technology Anymore. Strategy and Leadership. 25(6) 12-17.

Cusumano, M.A. 2011. Platform Wars Come to Social Media. Communications of the ACM. 54(4) 31-33.

Dai, T., Sahin, O., Tang, C.S. 2018. Sequential Screening on an Online Matching Platform. Working paper, Johns Hopkins University, Baltimore.

Damiano, E., Li, H. 2007. Price Discrimination and Efficient Matching. Economic Theory. 30(2), 243-263.

D'Angelo J.D., Toma. C.L. 2016. There Are Plenty of Fish in the Sea: The Effects of Choice Overload and Reversibility on Online Daters' Satisfaction With Selected Partners, Media Psychology, 20(1) 1-27.

Dellarocas, C. 2003. The Digitization of Word of Mouth: Promise and Challenges of Online Feedback Mechanism. Management Science. 49(10) 1407-1424.

Deloitte. 2016. Enterprise Crowdsourcing and the Growing Fragmentation of Work. https://www2.deloitte.com/content/dam/Deloitte/de/Documents/Innovation/us-cons-enterprisecrowdsourcing-and-growing-fragmentation-of-work $\% 20(3)$.pdf. Accessed on June 11, 2018.

Dougherty, C., M. Isaac. 2015. Airbnb and Uber Mobilize Vast User Base to Sway Policy. New York Times (November 4).

Du, L., Hu, M., Wu, J. 2017. Continuous Stimulus in Crowdfunding. Working paper, University of Toronto, Toronto. 
Economist. 2013. All Eyes on the Sharing Economy. https://www.economist.com/news/technology -quarterly/21572914-collaborative-consumption-technology-makes-it-easier-people-rent-items. Accessed on November 21, 2017.

EMarketer. 2016. Internet Users Rely on Reviews When Deciding Which Products to Purchase. https://www.emarketer.com/Article/Internet-Users-Rely-on-Reviews-Deciding-Which-ProductsPurchase/1014465. Accessed on December 5, 2017.

Ember, S. 2014. Start-ups Turn to the Crowd for Financing. New York Times. https://dealbook.nytimes .com/2014/12/10/start-ups-turn-to-the-crowd-for-financing/. Accessed on December 10, 2017.

European Commission. 2015. Communication from the Commission to the European Parliament, the Council, the European Economic and Social Committee and the Committee of the Regions. A Digital Single Market Strategy for Europe. COM/2015/0192 final. https://ec.europa.eu/digital-single-market/en Lnews/digital-single-market-strategy-europe-com2015-192-final. Accessed on November 27, 2017.

European Commission. 2017. Online Platforms. https://ec.europa.eu/digital-single-market/en/policies Lonline-platforms. Accessed on November 16, 2017.

Federal Trade Commission (FTC), 2016. The "Sharing" Economy: Issues Facing Platforms, Participants, and Regulations. A Federal Trade Commission Staff Report, November 2016.

Field, M. 2017. Alternatives to Uber: Apps to Use if Uber Is Banned. Telegraph.

http://www.telegraph.co.uk/technology/2017/09/22/alternatives-uber-apps-use-uber-banned/. Accessed on November 22, 2017.

Filieri, R. 2016. What Makes an Online Consumer Review Trustworthy? Annals of Tourism Research. 48 46-64.

Filieri, R., Alguezaui, S., McLeay, F. 2015. Why Do Travelers Trust Tripadvisor? Tourism Management. 51 174185.

Gee, K. 2017. New in Bumble’s Dating App: Swipe Right for Business Contacts. Wall Street Journal. https://www.wsj.com/articles/new-in-bumbles-dating-app-swipe-right-for-business-contacts-1510153200. Accessed on November 18, 2017.

Geoffrion, A.M., and Krishnan, R. 2003. E-Business and Management Science: Mutual Impacts (Part 1 of 2). Management Science. 49(10) 1275-1286.

Goldsmith, R.E. Horowitz, D. 2006. Measuring Motivations for Online Opinion Seeking. Journal of Interactive Advertising. 6 2-14.

Graham, L. 2017. Digital Games Market to See Sales Worth $\$ 100$ Billion This Year: Research. CNBC Video Game News. February 15, 2017. https://www.cnbc.com/2017/02/15/digital-games-market-to-see-salesworth-100-billion-this-year-research.html. Accessed on June 11, 2018.

Hackett, R. 2017. Walmart and 9 Food Giants Team Up on IBM Blockchain Plans. Fortune. http://fortune.com/2017/08/22/walmart-blockchain-ibm-food-nestle-unilever-tyson-dole/. Accessed on December 13, 2017.

Halaburda, H., Piskorski, M. J., Yildirim, P. 2017. Competing by Restricting Choice: The Case of Search Platforms. Forthcoming, Management Science.

Hennig-Thurau, T., Gwinner, K.P., Walsh, G., Gremler, D.D. 2004. Electronic Word-of-Mouth via Consumer-Opinion Platforms: What Motivates Consumers to Articulate Themselves on the Internet? Journal of Internet Marketing. 18(1) 39-52. 
House of Lords. 2016. Online Platforms and the Digital Single Market. https://publications.parliament.uk $\angle \mathrm{pa} / \mathrm{ld} 201516 /$ ldselect/ldeucom/129/129.pdf. Accessed on January 5, 2018.

Hu, M., Li, X., Shi, M. 2015. Product and Pricing Decisions in Crowdfunding. Marketing Science. 34(3) 331345.

Hu, M., Wang, L. 2017. Simultaneous vs. Sequential Crowdsourcing Contests. Working paper, University of Toronto, Toronto.

Jiang, Z., Huang, Y., Beil, D. R. 2016. The Role of Feedback in Dynamic Crowdsourcing Contests: A Structural Empirical Analysis. Working Paper, University of Michigan, Ann Arbor.

Jin, C., Hosanagar, K., Veeraraghavan, S. K. 2018. Do Ratings Cut Both Ways? Impact of Bilateral Ratings on Platforms. Working Paper, University of Pennsylvania...

Kabra, A., E. Belavina, K. Girotra. 2017. Designing incentives to scale marketplaces. Working Paper, INSEAD, Fontainebleau, France.

Kanoria, Y., Saban, D. 2017. Facilitating the Search for Partners on Matching Platforms: Restricting Agents' Actions. Working paper, Stanford University, Palo Alto.

Kickstarter. 2018. Kickstarter Stats. https://www.kickstarter.com/help/stats. Accessed on May 28, 2018.

Korpeoglu, C. G., Körpeoğlu, E., Tunç, S. 2018. Optimal Duration of Innovation Contests. Working Paper, University College London, London.

Korula, N., Mirrokni, V., Nazerzadeh, H. 2016. Optimizing Display Advertising Markets: Challenges and Directions. IEEE Internet Computing. 20(1) 28-35.

Körpeoğlu, E., Cho, S.-H. 2017. Incentives in Contests with Heterogeneous Solvers. Forthcoming, Management Science.

Körpeoğlu, E., Korpeoglu, C. G., Hafalır, İ. E. 2018. Contest among Contest Organizers. Working Paper, University College London, London.

Kuksov, Dmitri, J. Miguel Villas-Boas. 2010. When more Alternatives Lead to Less Choice. Marketing Science. 29(3) 507-524.

Li, J., Moreno, A., Zhang, D.J. 2015. Agent Behavior in the Sharing Economy: Evidence from Airbnb. Working paper, University of Michigan, Ann Arbor.

Li, J., Netessine, S. 2018. Market Thickness and Matching (In)efficiency: Evidence from a Quasi-Experiment. Working Paper, The Wharton School.

Luca, M. 2011. Reviews, Reputation, and Revenue: The Case of Yelp.com. Working Paper, Harvard Business School, Boston.

Luca, M., Zervas, G. 2016. Fake It Till You Make It: Reputation, Competition, and Yelp Review Fraud. Management Science. 62(12) 3412-3427.

Lucas, L. 2017. Questions Over Pace of Growth as WeChat Nears 1bn Users. Financial Times. https://www.ft.com/content/b557d6c8-8891-11e7-8bb1-5ba57d47eff7. Accessed on December 22, 2017. 
Michail, N., Teal, G., Basta, J., Austin, K.J. 2005. Internet information technology and "globalisation" redefining the meaning of information systems. 3rd International Conference on Politics and Information Systems: Technologies and Applications, Proceedings. Eds: Carrasquero, JV; Welsch, F; Oropeza, A; Flueier, T; Callaos, N.

Mihm, J., Schlapp, J. 2017. Sourcing Innovation: On Feedback in Contests. Forthcoming, Management Science.

Mollick, E. 2014. The Dynamics of Crowdfunding: An Exploratory Study. Journal of Business Venturing. 291 16.

Owen, D. 2018. Customer Satisfaction at the Push a Button. New Yorker (February 5).

Parker, G.G., Van Alstyne, M., and Choudary, S.P. 2016. Platform Revolution. Norton Publishers, New York.

Pew Research Center. 2016. Online Reviews. http://www.pewinternet.org/2016/12/19/online-reviews/. Accessed on December 19, 2016.

Riquelme, C., Banerjee, S., Johari, R. 2015. Pricing in Ride-Share Platforms: A Queuing Theoretic Approach. Working paper, Stanford University, Palo Alto.

Roma, P., Gal-Or, E., Chen, R.R. 2018. Reward-based Crowdfunding Campaigns: Informational Value and Access to Venture Capital. Forthcoming, Information Systems Research.

Rudder, C. 2010. Why You Should Never Pay for Online Dating. OkCupid. http://static.izs.me/why-youshould-never-pay-for-online-dating.html. Accessed on June 3, 2018.

Safronova, V. 2017. Instagram Is Now a Dating Platform, Too. Here's How It Works. New York Times. December 21, 2017. www.nytimes.com/2017/12/21/style/instagram-thirst-traps-dating-breakups.html. Accessed on January 3, 2018.

Scheiber, N. 2017. How Uber Uses Psychological Tricks to Push Its Drivers' Buttons. New York Times. https://www.nytimes.com/interactive/2017/04/02/technology/uber-drivers-psychological-tricks.html? $\mathrm{r}=0$ Accessed on December 18, 2017.

Schwartz, B. 2004. The Paradox of Choice: Why More is Less. Harper Perennial, New York, NY.

Slater, D. 2013. Love in the Time of Algorithms: What Technology Does to Meeting and Dating. New York, NY: Current.

Stevens, L., J. Emont. 2018. How Sellers Trick Amazon to Boost Sales. W all Street Journal (July 28).

Stouras, K., Girotra, K., Netessine, S. 2014. Liveops Inc.: The Contact Centre Reinvented. INSEAD Business School Case 6097, Harvard Business Publishing, Boston, MA.

Strausz, R. 2017. A Theory of Crowdfunding: A Mechanism Design Approach with Demand Uncertainty and Moral Hazard. American Economic Review. 107(6) 1430-1476.

Tang, C.S. 2012. How Groupon can Avert Death. UCLA Global Supply Chain Blog. http://blogs.anderson.ucla.edu/global-supply-chain/2012/10/how-groupon-can-avert-death-2.html

Tang, C.S., Yoo, O. 2018. Peak Period Pricing Strategies. Working Paper, University of California, Los Angeles.

Taylor, Terry. 2018. On-Demand Service Platforms. Manufacturing \& Service Operations Management. Forthcoming.. 
Terwiesch, C., Savin, S., Hann, I.H. 2005. Online Haggling at a Name-Your-Own-Price Retailer: Theory and Application. Management Science. 51(3) 339-351.

Terwiesch, C., Xu, Y. 2008. Innovation Contests, Open Innovation, and Multiagent Problem Solving. Management Science. 54(9) 1529-1543.

Van Dijck, J. 2013. The Culture of Connectivity: A Critical History of Social Media. Oxford University Press, New York, NY.

Van Alstyne, M.W., Parker, G.G., Choudary, S.P. 2016. 6 Reasons Platforms Fail. Harvard Business Review. March 31, 2016.

Veiga, A., E. G. Weyl, A. White. 2017. Multidimensional Platform Design. American Economic Review 107(5) $191-95$.

Wang, Y., Armstrong, P. 2017. Is Alibaba Doing Enough to Fight Fakes? Forbes. https://www.forbes.com Lsites/ywang/2017/03/10/is-alibaba-doing-enough-to-fight-fakes/\#2c963ffa5587. Accessed on December 20, 2017.

Wang, Z., Hu, M. 2014. Committed versus Contingent Pricing under Competition. Production and Operations Management, 23(11), 1919-1936.

Wooten, J., Ulrich, K. 2017. Idea Generation and the Role of Feedback: Evidence from Field Experiments with Innovation Tournaments. Production and Operations Management. 26(1) 80-99

Wright, J. 2004. One-sided Logic in Two-sided Markets. Review of Network Economics. 3(1) 44-64.

Wu, S.D., 2004. Supply Chain Intermediation: A bargaining theoretic framework. D. Simchi-Levi, S.D. Wu, Z.J. Shen, eds. Handbook of Quantitative Supply Chain Analysis: Modeling in the E-Business Era. Kluwer, London, 67-115.

Xiao, S., Chen, Y.J., Tang, C.S. 2017. Knowledge Sharing and Learning among Smallholders in Developing Economies: Implications, Incentives, and Reward Mechanisms. Working Paper, University of California, Los Angeles.

Yoo, K. H., Gretzel, U. 2008. What Motivates Consumers to Write Online Travel Reviews? Information, Technology, and Tourism. 10 283-295.

Yu, J., Shen, M., Tang, C.S. 2017. Should On-Demand Ride Services be Regulated? An Analysis of Chinese Government Policies. Working Paper, University of California Los Angeles.

Zachary, G. P. 2008. “The amazing race,” as played in the lab. New York Times (March 16).

Zhu, F., and Furr, N. 2016. Products to Platforms: Making the Leap. Harvard Business Review. April. 3-8.

Zhu, F., Zhang, M. 2010. Impact of Online Consumer Reviews on Sales: The Moderating Role of Product and Consumer Characteristics. Journal of Marketing. 74(2) 133-148. 